\title{
Effects of Date of Inoculation on the Within-Plant Movement of Xylella fastidiosa and Persistence of Pierce's Disease Within Field Grapevines
}

\author{
Helene Feil, William S. Feil, and Alexander H. Purcell
}

Division of Insect Biology, University of California, Berkeley 94720.

Accepted for publication 18 October 2002.

\section{ABSTRACT}

Feil, H., Feil, W. S., and Purcell, A. H. 2003. Effects of date of inoculation on the within-plant movement of Xylella fastidiosa and persistence of Pierce's disease within field grapevines. Phytopathology 93:244-251.

The effects of date of inoculation on the development of Pierce's disease (PD) were evaluated in California grapevines during 1997 through 2000 at four locations. Some vines that had been inoculated either by using blue-green sharpshooters (Graphocephala atropunctata) as vectors or mechanically by needle puncture with the PD causal bacterium Xylella fastidiosa became infected during each month and at each location where infection was attempted. Vines inoculated on the earliest inoculation dates (April to May) developed more extensive and severe PD symptoms, and only $54 \%$ of these vines recovered from PD after the following winter, compared with vines that had been inoculated during June through August, of which 88\% recovered from PD after the following winter. For the 1999 inoculations, the number of vines infected at a central California site (Parlier) was higher than the number of vines infected at a north coastal site (Hopland). For the best-fitting regression equation, percent recovery of vines infected with $X$. fastidiosa increased significantly with date of inoculation $\left(r^{2}=0.737\right)$ at all sites excluding Hopland. The Hopland site had the highest percentage of vines that recovered from PD (100\%). At most sites, only early infection (April and May) resulted in chronic disease unless the vines were inoculated at the bases instead of the distal tips of canes. Vines inoculated early in the growing season (April and May) have less chance to recover from Pierce's disease than vines inoculated later (July and August).

Additional keyword: recovery, Vitis vinifera.
Pierce's disease (PD) is an economically important disease of grapevines (Vitis vinifera L.) caused by Xylella fastidiosa Wells et al. (24), a fastidious, xylem-inhabiting bacterium (3). The principal vector in the coastal grape-growing regions of California is the blue-green sharpshooter (BGSS), Graphocephala atropunctata (Signoret) (family Cicadellidae) (17,20). In California coastal vineyards, the highest incidence of $\mathrm{PD}$ occurs near riparian areas in which the vectors reside $(9,16)$. The spatial patterns of PD in Napa Valley vineyards along riparian habitats resembled the early spring spatial patterns of BGSS within vineyards, but were not similar to mid- to late summer spatial patterns of BGSS (17). This suggests that late-inoculated vines may not have become infected or may have recovered from infection. Indeed, some infected vines appeared to have recovered from $\mathrm{PD}$ when mapped in successive years (16).

Transmission experiments in two regions in California showed that early-season (April to June) inoculations consistently caused PD symptoms that persisted beyond the subsequent winter (hereafter referred to as chronic infection), whereas inoculations in July and August caused chronic infection far less frequently (19). However, these experiments were done before culturing methods for $X$. fastidiosa were developed; therefore, infections were inferred solely from PD symptoms. We conducted similar experiments to determine the effects of inoculating vines at different dates during the growing season and used culturing to confirm infection with $X$. fastidios $a$ and to estimate the speed and extent of intraplant movement of $X$. fastidiosa to test the hypothesis that

Corresponding author: A. H. Purcell; E-mail address: purcell@nature.berkeley.edu

Publication no. P-2002-1217-01R

(c) 2003 The American Phytopathological Society early PD infections are more persistent and more severe than late infections, as was suggested by the earlier studies (19).

Temperature appears to influence the incidence of PD in at least the following ways: (i) $X$. fastidiosa generally occurs in geographical areas with mild winter climates $(13,18)$, (ii) PD symptoms appear earlier and become more severe in warmer climates $(8,9)$, (iii) the incidence of PD increases at the margins of its geographic distribution following warmer-than-average winters (13), and (iv) freezing treatments can cure vines of PD $(5,18)$. Therefore, for our study, we inoculated vines at various dates from spring through summer to assess the effects of date of inoculation on the persistence over winter of $X$. fastidiosa in infected vines. We used experimental sites both in cooler coastal locations and in warmer central California sites to investigate possible regional differences in the extent and time of appearance of PD symptoms, as well as the overwinter survival of $X$. fastidiosa.

\section{MATERIALS AND METHODS}

Bacterial strains, culture, and inoculation methods. $X$. fastidiosa strain STL (ATCC 700963), from grape in Napa Valley, CA, was used during the 1997 to 1999 inoculations. Strain Medeiros (ATCC 700966), collected from grape in Fresno County, CA, was used in some of the 1998 field inoculations. We used two strains of $X$. fastidiosa for the inoculations to make sure that the results obtained were not specific to a single strain. Cells of $X$. fastidiosa were grown in liquid periwinkle wilt (PW) medium (4) or on a modified version of PW solidified with gellan gum (PWG medium) (10) (Gelrite; Sigma-Aldrich, St Louis). Rooted cuttings of grapevines (Cabernet Sauvignon) were needle inoculated (14) in the greenhouse with strain STL to use as acquisition sources for infecting sharpshooter vectors to be used for the field inoculations. We collected BGSS from a public rose garden in Berkeley 
or from lab-reared nymphs on California mugwort (Artemisia douglasiana Besser), which supports low, nonsystemic populations of $X$. fastidiosa (10). BGSS nymphs were transferred to new plants every 2 to 3 days. Newly molted BGSS adults were caged on healthy grapes. These BGSS were presumed to be noninfectious because the grapes on which they had been caged did not develop PD symptoms. These noninfectious new adult BGSS were allowed to acquire $X$. fastidiosa by feeding for 2 days on PDsymptomatic, greenhouse-grown rooted cuttings of grape previously determined to be infected with the STL strain of the bacterium. The BGSS were allowed to feed ad lib on stem, leaf, or petiole during the 2 days of acquisition. After acquisition, we placed the BGSS in groups of 20 on healthy vines to determine their infectivity. We did not wait for the symptoms to appear on these vines before we used the BGSS for the field inoculations. However, we later recorded if the vines were positive, indicating whether at least some of the group of BGSS used in the study had been infective.

Field inoculation. We inoculated established grapevines donated for our experiments at two coastal locations (Oakville, $38^{\circ} 26^{\prime} \mathrm{N}, 122^{\circ} 24^{\prime} \mathrm{W}$, and Hopland, $39^{\circ} 00^{\prime} \mathrm{N}, 123^{\circ} 06^{\prime} \mathrm{W}$ ) and two interior sites in the Central Valley (Davis, $38^{\circ} 31^{\prime} \mathrm{N}, 121^{\circ} 47^{\prime} \mathrm{W}$, and Parlier, $36^{\circ} 36^{\prime} \mathrm{N}, 119^{\circ} 30^{\prime} \mathrm{W}$ ) during 1997 to 1999 . Except for the privately owned Hopland site, the other sites were located in University of California vineyards maintained by the Department of Viticulture and Enology at Davis and Oakville or the Kearney Agricultural Center at Parlier. An additional site of mature Merlot vines on AXR rootstock at Knight's Valley in Sonoma County was added in 2001 to evaluate the overwinter recovery rate from PD because PD has never been observed in this location despite the presence of BGSS vectors and suitable riparian host plants for $X$. fastidiosa adjacent to vineyards. The vines had been trained to two lateral permanent branches (cordons) on a trellis wire and spur-pruned (leaving several two-node spurs on each cordon), except for the vines at Davis, which were pruned to leave only a single cane with approximately eight nodes from the previous year's growth (cane-pruned). Vines were spaced 2.3 by $3.0 \mathrm{~m}$ (1,435 vines per hectare) in all vineyard sites. Each experimental block contained approximately 300 vines within established vineyards. The ages and cultivars at each site were approximately 20-year-old Cabernet Sauvignon scions on AXR1 rootstocks at Oakville; 30-year-old, self-rooted cuttings of Cabernet Sauvignon at Davis; 10-year-old, self-rooted cuttings of Ruby Cabernet in Parlier; and 5-year-old Chardonnay scions on AXR1 rootstocks in Hopland. The Oakville and Davis vineyards had conditions that made distinguishing PD symptoms more difficult: widespread measles, a disease of uncertain etiology (marginal and spotted leaf discoloration and necrosis and fruit raisining), Eutypa die-back caused by the fungus Eutypa lata (deformation and discoloration of the shoots, necrotic spots on leaves, fruit cluster with a mixture of large and small berries) (7-9) in Davis, and phylloxera-weakened vines as well as some vines with natural spread of PD in a nearby plot at Oakville. Other problems we encountered at some sites were unplanned pruning by vineyard crews at Davis that removed canes we wished to harvest, and the premature termination in 2000 of our experiments at Parlier and Davis because of concerns about the recent invasion of a newly established PD vector, the glassy-winged sharpshooter (GWSS; Homalodisca coagulata (Say)). In addition, the Oakville and Hopland sites had some natural spread of PD in the same or adjacent blocks, but the rate of new infections never exceeded 3\% at Oakville or $1 \%$ at Hopland throughout our studies at these locations. A problem at the Knight's Valley site was some decline from phylloxera.

For the 1997-98 inoculations (Oakville and Davis), we used BGSS to inoculate the STL strain of X. fastidiosa. The following year we used both BGSS and mechanical (needle) inoculations of strains STL and Medeiros. In 1999, we made all inoculations by needle. For BGSS inoculations, we confined the infective BGSS in small plastic cages containing a grapevine leaf in the laboratory, transported the cages to the field site, and introduced the small cages into 38-by-60-cm dacron organdy sleeve cages. This material is similar to nylon mesh and allows sufficient air and sunlight to pass through but prevents the escape of BGSS. Each sleeve cage contained four adult BGSS and was arranged with no additional support on approximately five nodes along one cane per vine, extending basally beginning seven nodes from the tip of the cane because BGSS strongly prefers feeding on succulent plant tissue found on new growth at the tips of the canes (17). After securing the sleeve cage openings with string or wire, we removed the lid or sponge plug from the plastic cages to release the insects into the sleeve cages. Two days after introducing the BGSS into cages, we sprayed the cages with Resmethrin insecticide (Whitmire Research Laboratory, Inc., St. Louis) and removed the sleeve cages with the dead BGSS after $8 \mathrm{~h}$. For the BGSS inoculations, vines were inoculated with the sleeve covering approximately five nodes basal to the seven apical nodes or with the sleeve cage covering approximately six to seven nodes for the August basal inoculations. When needle inoculations were conducted, we chose a leaf petiole on two adjacent leaves nearest to the cordon for the July and August basal inoculations and seven nodes from the tip for the apical inoculations. The sites, set-up dates, types of inoculations, and numbers of vines inoculated are summarized in Table 1. Control vines were needle inoculated with phosphatebuffered saline solution.

TABLE 1. Summary of experimental sites, dates, types, locations of inoculations, and number of vines inoculated

\begin{tabular}{|c|c|c|c|}
\hline $\begin{array}{l}\text { Site, year, } \\
\text { date of inoculation }\end{array}$ & $\begin{array}{c}\text { Type of } \\
\text { inoculation }^{\mathrm{a}}\end{array}$ & $\begin{array}{c}\text { Part of cane } \\
\text { inoculated }\end{array}$ & $\begin{array}{c}\text { Number of vines } \\
\text { inoculated }\end{array}$ \\
\hline \multicolumn{4}{|l|}{ Oakville, 1997} \\
\hline 7 April & BGSS & Tip & 15 \\
\hline 7 May & BGSS & Tip & 13 \\
\hline 7 June & BGSS & Tip & 12 \\
\hline 8 July & BGSS & Tip & 13 \\
\hline 19 August & BGSS & Tip & 12 \\
\hline 19 August & BGSS & Base & 12 \\
\hline \multicolumn{4}{|l|}{ Davis, 1997} \\
\hline 15 April & BGSS & Tip & 12 \\
\hline 14 May & BGSS & Tip & 12 \\
\hline 13 June & BGSS & Tip & 12 \\
\hline 11 July & BGSS & Tip & 12 \\
\hline 21 August & BGSS & Tip & 12 \\
\hline 21 August & BGSS & Base & 12 \\
\hline \multicolumn{4}{|l|}{ Davis, 1998} \\
\hline 5 May & BGSS & Tip & 12 \\
\hline 5 May & Needle & Tip & 26 \\
\hline 24 June & BGSS & Tip & 12 \\
\hline 24 June & Needle & Tip & 13 \\
\hline 27 July & BGSS & Tip & 12 \\
\hline 27 July & BGSS & Base & 12 \\
\hline 27 July & Needle & Tip & 24 \\
\hline \multicolumn{4}{|l|}{ Parlier, 1998} \\
\hline 7 May & BGSS & Tip & 12 \\
\hline 7 May & Needle & Tip & 27 \\
\hline 26 June & BGSS & Tip & 12 \\
\hline 26 June & Needle & Tip & 24 \\
\hline 29 July & BGSS & Tip & 12 \\
\hline 29 July & BGSS & Base & 12 \\
\hline 29 July & Needle & Tip & 24 \\
\hline \multicolumn{4}{|l|}{ Parlier, 1999} \\
\hline 24 April & Needle & Tip & 20 \\
\hline 2 June & Needle & Tip & 20 \\
\hline 7 August & Needle & Tip & 12 \\
\hline 7 August & Needle & Base & 12 \\
\hline \multicolumn{4}{|c|}{ Knight's Valley, 2001} \\
\hline 26 April & Needle & Tip & 20 \\
\hline 14 May & Needle & Tip & 6 \\
\hline
\end{tabular}

a $\mathrm{BGSS}=$ blue-green sharpshooter. 
Collection of samples. At all sites in late summer following the inoculations, we recorded symptoms and collected samples of leaves with PD symptoms or, if no symptoms were expressed, from the oldest leaf near the inoculation point. We transported the collected leaves to the laboratory in plastic bags, stored on ice in an ice chest. At Parlier, we collected samples during June, at the end of July, and at the beginning of August 2000 to estimate bacterial populations through the season. We chose culturing as a sensitive detection method because we needed to detect viable cells to confirm the diseased condition of the vine as PD. We confirmed vines as actively infected by $X$. fastidiosa by sampling according to the method of Hill and Purcell (10). Grape petioles ( 0.1 to $0.2 \mathrm{~g}$ ) were surface sterilized, cut aseptically with a razor blade into small (0.5 to $1 \mathrm{~mm})$ segments, and homogenized in $2 \mathrm{ml}$ of sterile phosphate-buffered saline using a Polytron homogenizer (Brinkman Instruments, Inc., Westbury, NY). Droplets $(20 \mu \mathrm{l})$ of homogenated tissue and two 100-fold dilutions of each were spread on PWG plates. The plates were incubated at $28^{\circ} \mathrm{C}$ until colonies of $X$. fastidiosa could be seen on plates. The detection threshold for culturing was calculated as less than $10^{3}$ cells per gram of plant tissue (10). In comparison, the sensitivity of a serological enzyme-linked immunosorbent assay detection threshold was calculated as greater than $10^{5}$ cells per gram of plant tissue (12) and does not give any information on cell viability.

Collection of cuttings. To determine the spread of the bacterium along inoculated canes, we harvested the inoculated canes in late winter, leaving two-node spurs on the cordon. We cut each collected cane into three-node cuttings, measured the length of each cutting, labeled the vine number and position on the cane, and rooted alternate cuttings upright in pots containing a modified University of California (UC) mix (1) called UC Davis mix potting media (one-third course sand, one-third peat, and one-third fine fir bark). The pots were placed in the greenhouse for rooting and symptom development. For the 1997 inoculations, cuttings from the Oakville and Davis sites were collected on 10 and 14 February 1998 and rooted in pots 1 day later. At Oakville, 72 out of 76 inoculated canes were retrieved, from which 297 cuttings were rooted. At Davis, the working crew had pruned off the canes, but we retrieved 49 out of the 72 inoculated and labeled canes from the ground and 188 cuttings were rooted. For the 1998 inoculations, we collected 106 and 122 canes and rooted 374 and 382 cuttings from the Davis and Parlier sites on 10 and 15 February 1999, respectively. After 3 and 6 months in the greenhouse, we cultured, according to the method described previously, from petioles of each successfully rooted cutting to determine if $X$. fastidios $a$ was present and calculated the length of cane infected.

Statistics. A regression analysis was performed to relate percent recovery from PD (number of infected vines from which no $X$. fastidiosa could be detected the following year) to the times of inoculation using the nonlinear regression function $y=\left(1-e^{-a x}\right)^{b}$ from SigmaPlot 2001 (SPSS, Chicago). Hopland was excluded because all the vines recovered from PD a year following the inoculation at that site. An analysis of variance (ANOVA) was performed for a split-plot design with years as blocks, site as the main-plot factor, and date of inoculation as the subplot factor according to Little and Hills (15) for the two replicated sites Davis and Parlier to estimate the effects of location and inoculation period (early-, middle-, or late-season) on the percentage of vines that recovered from PD. To compare the length of canes for which we could detect $X$. fastidiosa from the point of inoculation for the different dates of inoculations at the sites, we used a one-way ANOVA followed by a mean separation using Fisher's least significant difference (LSD) test using SigmaStat 2.03 (SPSS).

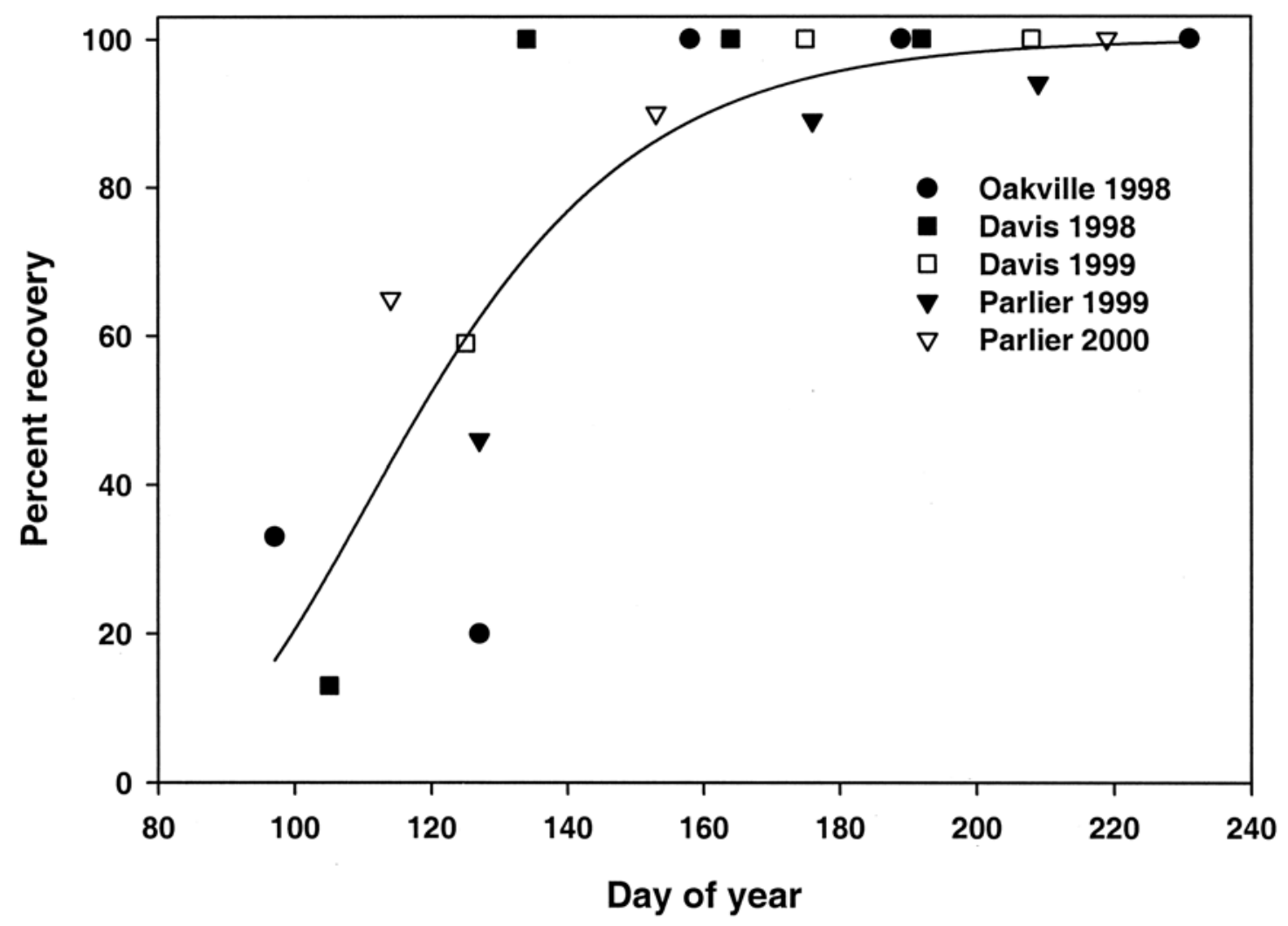

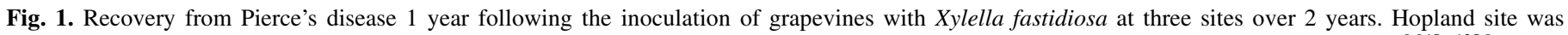

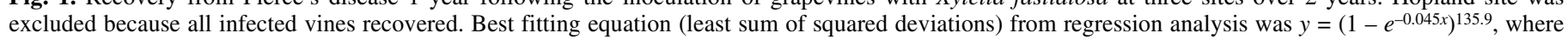
$y=$ percent recovery and $x=$ date of inoculation $\left(r^{2}=0.737\right)(P<0.0001)$. 


\section{RESULTS}

In late summer, for all years and all sites, the symptoms resulting from the early-season inoculations were more severe (i.e., more leaves scorched on more canes) than the symptoms resulting from the mid- and late-summer inoculations. Three months following the May inoculation at the Davis site, the first symptom to appear on Cabernet Sauvignon vines was a slight discoloration (entire leaf yellow or reddish) and marginal scorching on some leaves within the inoculated section nearest the point of inoculation. In late summer, most infected canes were symptomatic throughout their length and, 2 years later, the entire vine typically was dead or nearly dead. Fall symptoms resulting from the April or May inoculations generally occurred along the entire inoculated cane and on one or more adjacent canes. June or July inoculations

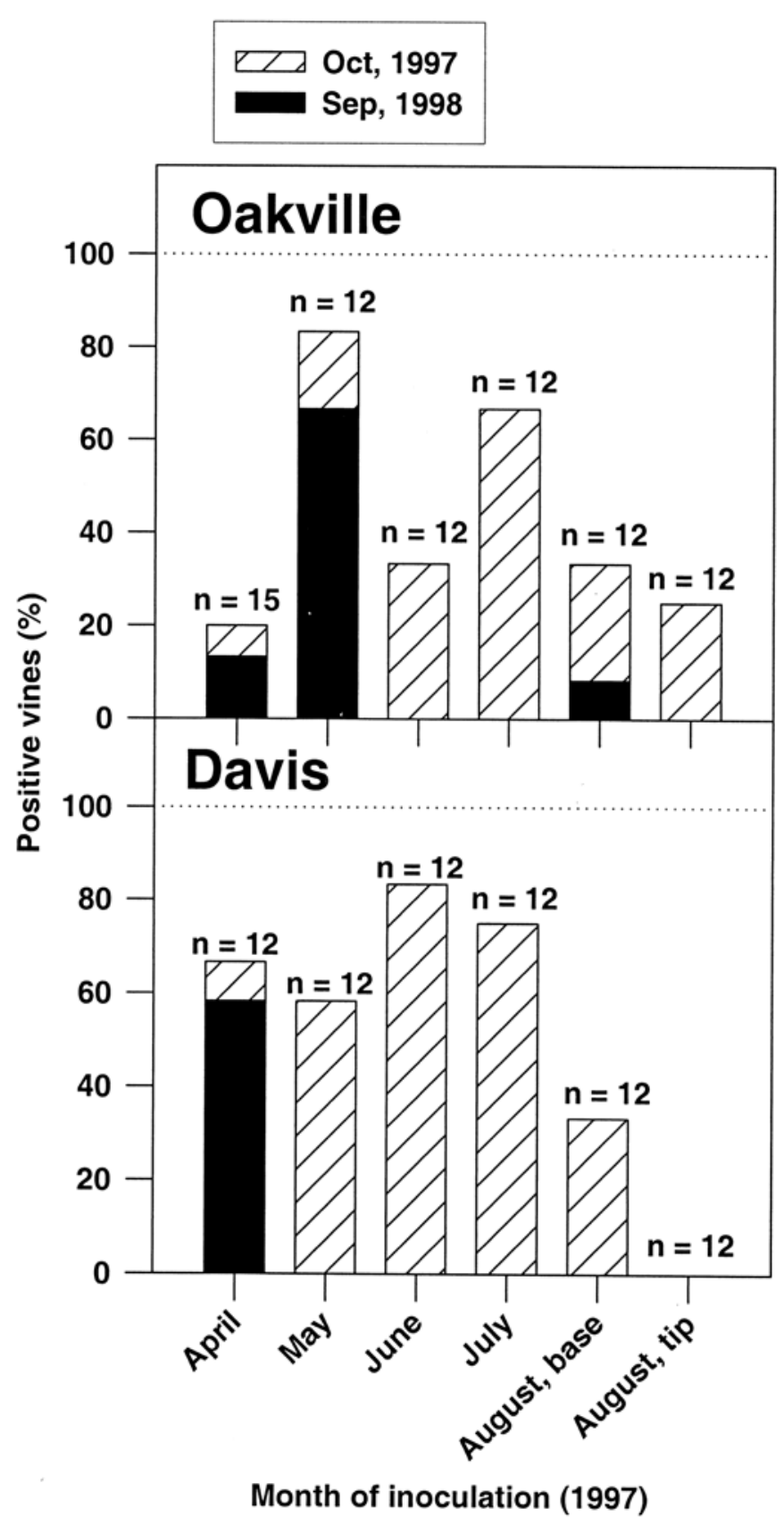

Fig. 2. Percentage of vines from which Xylella fastidiosa, the causal agent of Pierce's disease, was cultured in 1997 and 1998 following blue-green sharpshooter inoculations during 1997 at Oakville and Davis; $n=$ number of canes inoculated. usually resulted in leaf scorch symptoms occurring mostly at the tip of the inoculated cane, whereas August inoculations resulted in usually uniform yellow or red discoloration on the two inoculated leaves of the inoculated canes. On 21 June 1999 at the Hopland site, the most severe symptoms resulting from early-season inoculations were slightly shriveled berries on the basal clusters; whereas, in late summer, the symptoms included discolored and dried leaves and berries all along the inoculated cane. For midand late-season inoculations, symptoms by late summer or early October occurred only on leaves within the inoculated section.

There was a strong trend for early-season inoculations to recover from infections with $X$. fastidiosa less frequently than middle- or late-season inoculations (Fig. 1). Recovery of vines infected with $X$. fastidiosa increased with later dates of inoculation $\left(r^{2}=0.737\right)$, as summarized in the regression equation fitted to the

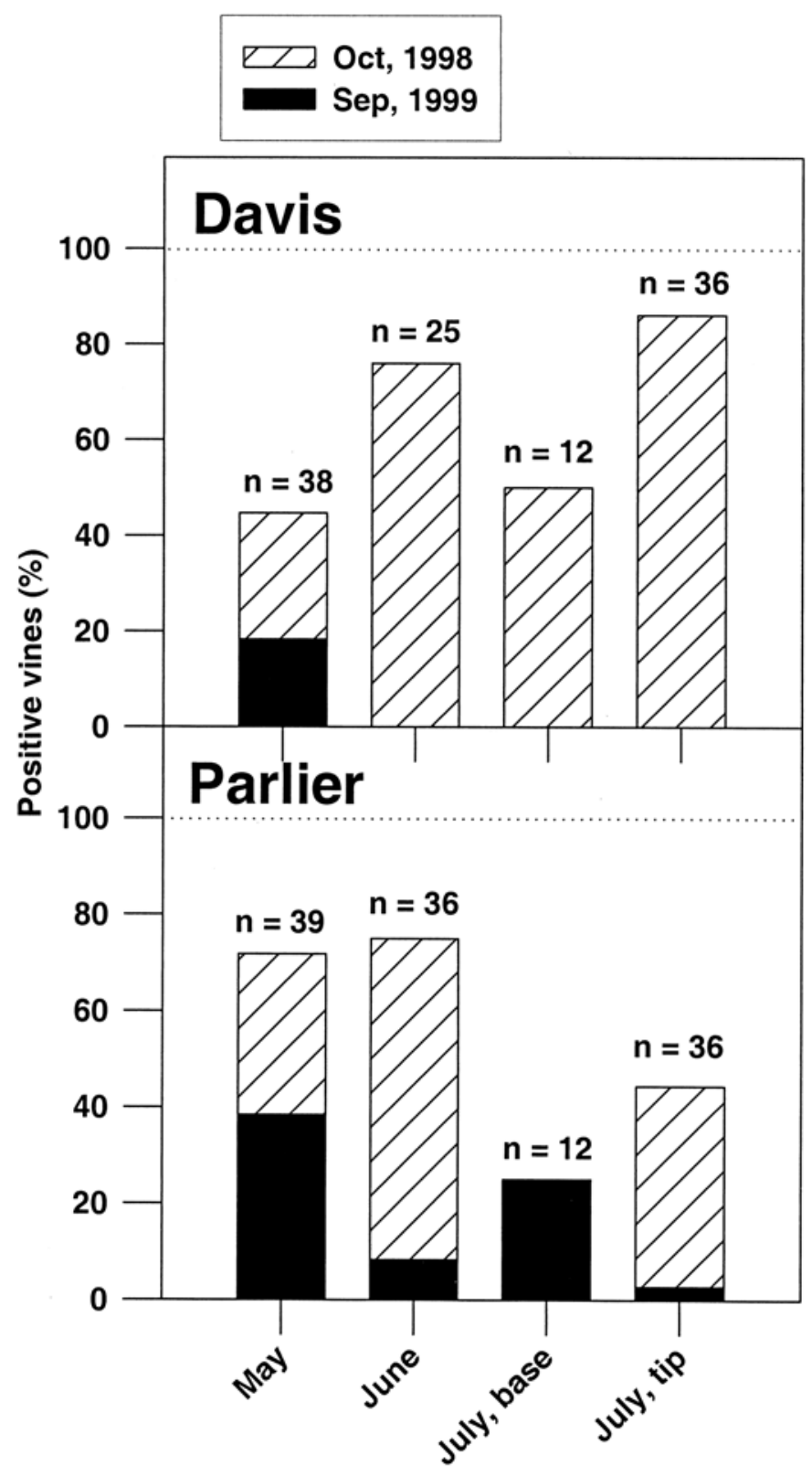

Month of inoculation (1998)

Fig. 3. Percentage of vines from which Xylella fastidiosa, the causal agent of Pierce's disease, was cultured in 1998 and 1999 following blue-green sharpshooter or mechanical inoculations during 1998 at Davis and Parlier; $n=$ number of canes inoculated. 
data. The disease incidence for each of two sites used during 1997 to 2000 is summarized in Figures 2 through 4. An ANOVA between percent plant recovery from PD (at the two sites for which we had replicated data over years) and date of inoculations (Table 2) showed that the differences in the mean values between the two sites was not statistically significant $(P>0.1)$, but that the difference in the mean values among the time of inoculations were statistically significant $(P<0.01)$. For the 1997 inoculations, the highest percentage of inoculated vines at the Oakville and Davis sites that were chronically infected (did not recover from PD over the winter) were those that had been inoculated in April and May (Fig. 2). Only one vine inoculated at the base in August at the Oakville site did not recover from PD the following year (Fig. 2). We detected $X$. fastidiosa in very few vines that had been inoculated with BGSS in August (Fig. 2). For the 1998 inoculations, the highest number of chronic infections occurred for the

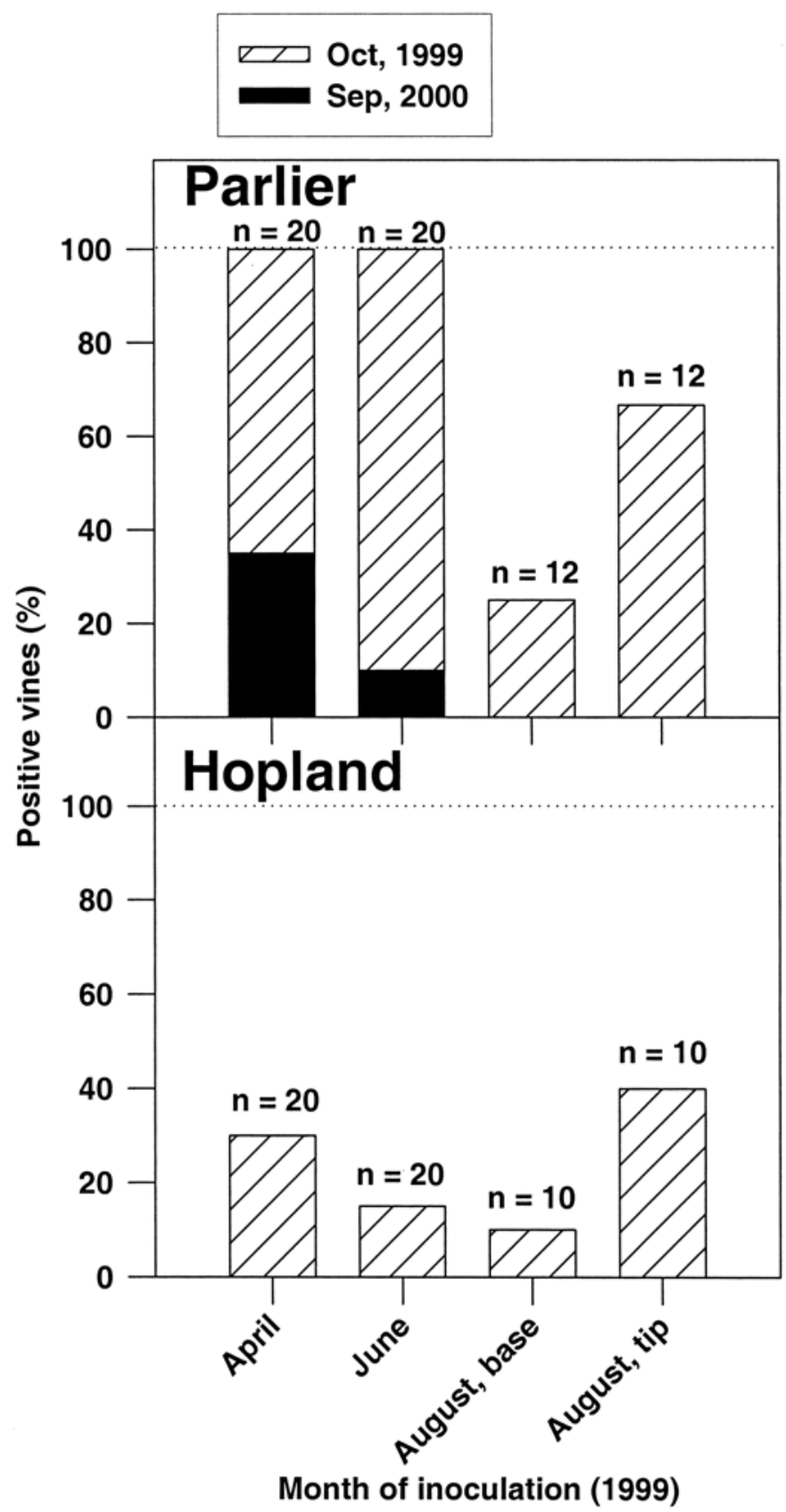

Fig. 4. Percentage of vines from which Xylella fastidiosa, the causal agent of Pierce's disease, was cultured in 1999 and 2000 following mechanical inoculations during 1999 at Parlier and Hopland; $n=$ number of canes inoculated.
May inoculations at the Davis and Parlier sites (Fig. 3). A few vines from the June and July inoculations became chronically infected at the Parlier site, the warmest site in our study. All three infected vines from infections established at the bases of canes in July 1998 at Parlier remained infected the next year. For the 1999 inoculations at Parlier, the lowest recovery again was for earlyseason (April) inoculations (Fig. 4). By contrast, no infections that were confirmed in 1999 at Hopland persisted until 2000 or 2001. None of the infections resulting from the August 1999 inoculations (base or tip of cane) persisted the following year at the Parlier and Hopland sites (Fig. 4). Early-season (April to May) inoculations resulted in chronic infections, whereas mid- or lateseason (June to August) cane tip inoculations resulted in infections that did not persist the following year. Pooling all sites and years except for Hopland (because at Hopland no infection became chronic), only a few inoculations of petioles at the basal portions of canes during July (4 out 73 infected vines) and August ( 1 out of 22 infected vines) established chronic infections. At Knight's Valley in 2001, 21 of the 26 inoculated Merlot vines developed PD symptoms and were positive for $X$. fastidiosa by culturing. PD symptoms were evident by 26 July 2001, but only approximately half of the vines had marginal leaf scorch; the remainder had some uniformly yellow or red-colored leaves on symptomatic canes. By October 2001, PD symptoms appeared on more than one cane on almost all vines, indicating movement of $X$. fastidiosa into the cordon to reach other canes on the same cordon. The following September (2002), 16 of the 21 formerly diseased vines had no PD symptoms and we cultured $X$. fastidiosa only from the remaining 5 vines that still had PD symptoms. Half of the vines that had recovered had noticeably shorter new canes from the spur left by winter pruning of an inoculated shoot but had no foliar PD symptoms and were negative by culture from two basal leaves from each cane. Pruners had removed most of the cordons from six of the vines with PD in 2001, presumably because they encountered dead wood in the cordon, but four of these vines had no evidence of PD or of $X$. fastidiosa in the fall of 2002.

Approximately $30 \%$ of the cuttings collected at the end of the winters of 1997 and 1998 either did not root or died after rooting in the greenhouse before they could be evaluated for the presence of $X$. fastidiosa. Out of the remaining growing cuttings, only rooted cuttings from inoculated canes that were found positive for $X$. fastidiosa during the fall following the inoculations were positive for $X$. fastidiosa. We calculated that $96 \%$ of positive canes from fall diagnoses were positive from one or more rooted cuttings from each cane. Because we were only interested in recording the extent of the movement of $X$. fastidiosa along the cane, we only included canes that we had verified the preceding fall as infected to calculate the average length of bacterial movement. For the May 1997 inoculations at the Oakville site, the average length of infected cane from the inoculated cane was significantly longer than for the August inoculations according to Fisher's LSD test $(P<0.05)$ (Fig. 5). For the May and June 1998 inoculations at Davis, the lengths of cane infected with $X$. fastidiosa were significantly longer than the ones for the July inoculations. The average length of infected cane was not significantly longer for the July 1998 inoculations done at the base of the cane compared with those done at the tip of the canes in Davis and in Parlier (Fig. 5). We could not calculate distance traveled by the bacteria for the 1999 inoculations because, at both sites, the maintenance crew pruned off the inoculated canes before we could collect them. At the Parlier site, symptoms occurred on canes adjacent to the inoculated cane, indicating that $X$. fastidiosa had spread to within the cordon. Pruning in late winter may have removed all infected portions of the canes from some vines, leaving an uninfected vine. For example, at the Davis site for the 1998 July inoculations, we detected X. fastidiosa in one or more cuttings from 15 inoculated canes the following year, even though 
the vines from which these canes were collected were found to have recovered from PD by the next fall (Fig. 2).

\section{DISCUSSION}

Our results confirmed that, for all sites and years of this study, infections of $X$. fastidiosa from April and May inoculations persisted at higher percentages after the subsequent winter than those from June, July, and August inoculations. Some vines infected during each inoculation period, even some with extensive PD symptoms on more than one cane, recovered from PD after one winter. It is not possible by diagnostic testing to prove that a plant is completely free of a given pathogen, but the strong trends revealed by this study clearly indicate that both disease symptoms and the detectable persistence of $X$. fastidiosa decrease the later during the growing season in which $X$. fastidiosa is introduced into the plant. April and May infections generally spread to adjacent canes on the same cordon by September or October of the same season.

Symptom development was similar at the Oakville and Davis sites for the 1997 inoculations, but PD symptoms were much more severe during the fall immediately following inoculation at the Parlier site than at the Davis and Hopland sites for the 1998 and 1999 inoculations, respectively. This difference probably can be attributed to the warmer temperatures occurring at the Parlier site, which may have increased early population growth of $X$. fastidiosa, and to water stress caused by high temperatures (6). The grape cv. Chardonnay was used at Hopland. This is a cultivar more susceptible to $X$. fastidiosa than 'Cabernet Sauvignon' or 'Ruby Cabernet' $(8,16,19)$, and makes the complete recovery of all vines that we inoculated at Hopland even more surprising because susceptible cultivars have lower recovery percentages than do less susceptible cultivars $(16,19)$. Similarly, the high rate of recovery (76\%) at the Knight's Valley site from April and May inoculations was particularly striking because the infected vines all had severe symptoms on more than a single cane. At all sites for all dates, BGSS inoculations resulted in lower levels of $X$. fastidiosa transmission than would have been predicted from previous studies on transmission efficiency done in the greenhouse, in which 4 BGSS per plant for 2 days should have produced nearly $100 \%$ disease incidence (11).

We were able to detect $X$. fastidiosa in cuttings generated from canes inoculated in July or August 1997 and 1998 and collected in February of the following year, despite the lack of PD symptoms on most of these vines and no detectable bacteria the following year, suggesting that either the bacteria were localized within the collected inoculated canes, or that the surviving $X$. fastidiosa died out later than in early February, when the canes were collected. Our data further support the conjecture (18) that summer infections of vines with $X$. fastidiosa were relatively unimportant in establishing chronic PD (i.e., most summer infections did not persist until the next growing season). Secondary, or vine-to-vine, spread of $X$. fastidiosa can occur only when $X$. fastidiosa populations are sufficient for vector acquisition (12). The bacterium was detected by culturing or polymerase chain reaction from the new growth of most chronically infected vines in Napa Valley only after June, and then only in low populations until late July or August (22) within basal leaf petioles of chronically infected vines. The distal portions of stems, where BGSS prefer to feed (17), would support even lower populations of $X$. fastidiosa. Thus, vine-to-vine spread of $X$. fastidiosa would be likely only during summer months. The lack of summer infections persisting until the following growing season, rather than the absence of vine-to-vine spread of $X$. fastidiosa, thus would explain the lack of evidence for secondary spread of PD.

Along with the lower recovery for April and May inoculations, the length of inoculated cane that the bacteria colonized was higher for the vines inoculated in April or May compared with vines inoculated in June, July, or August. We estimated movement of $X$. fastidiosa only within canes; therefore, the distance of movement of $X$. fastidiosa beyond canes' bases exceeded our estimates of minimum distance of movement of $X$. fastidiosa. It is likely that at least some vines recovered from summer inoculations because the bacteria did not move into cordons and dormant pruning eliminated the infected part of the cane. On the other hand, numerous vines inoculated at all sites in April or May of 1997, 1998, or 1999 had several canes with symptoms during the following fall, indicating that $X$. fastidiosa had reached the cordon, yet many of these vines recovered from PD. The striking difference between recovery for May inoculations at Davis in 1997 (100\%) and 1998 (58\%) compared with May inoculations at Oakville in 1997 (33\%) or Parlier in 1998 (46\%) may have been caused in part by the head-trained, cane-pruning system used at Davis (each winter the previous season's fruiting canes are pruned off to the main trunk except for two canes on each side of the trunk). The cane-pruning system would require $X$. fastidiosa to move a greater distance to reach a portion of the vine that was not pruned during winter.

Our finding that the later during the growing season infection by $X$. fastidiosa occurred, the less the chance that the infection would persist until the following year strongly suggests that it is critical to exclude vectors from entering vineyards in the early season. In Napa Valley, for example, April and May would be the most vulnerable periods for establishing chronic infections, because BGSS populations are very low in June (17) and infections made after June are unlikely to persist until the following season.

The recent establishment of GWSS in California drastically increased the spread of PD where GWSS inhabited vineyards $(2,21)$. This increase may represent the expected exponential rate of disease incidence increase that secondary (vine-to-vine) spread of $X$. fastidiosa within vineyards would produce. The establishment of chronic $X$. fastidiosa infections by GWSS inoculations of the basal portions of canes or even spurs during summer months or even during fall and winter would increase the likelihood that the summer or vine-to-vine phase of bacterial transmission would become an important factor for the spread of chronic infections. Experimental data are needed to test this hypothesis. PD has been cited as a classic example of "simple interest disease" (22), without evidence of secondary spread. The failure of rouging vines with PD to reduce the incidence of PD in later years (9) and the

TABLE 2. Analysis of variance for percentage of vines that recovered from Pierce's disease by site (Davis versus Parlier) and date of inoculation for 2 years (year 1 and year 2 of the study)

\begin{tabular}{|c|c|c|c|c|c|}
\hline Source of variance & df & Sum of squares & Mean squares & $F$ & $P$ \\
\hline Subplots & 11 & $4,696.25$ & $\ldots$ & $\ldots$ & $\ldots$ \\
\hline Main plots & 3 & 440.25 & $\ldots$ & $\ldots$ & $\ldots$ \\
\hline Blocks (year) & 1 & 184.08 & 184.08 & $\ldots$ & $\ldots$ \\
\hline Main plot error & 1 & 102.08 & 102.08 & & \\
\hline Date of inoculation & 2 & $4,056.00$ & $2,028.00$ & 60.84 & $<0.01$ \\
\hline Site $\times$ date & 2 & 66.67 & 33.33 & 1.00 & $>0.10$ \\
\hline Subplot error & 4 & 133.33 & 33.33 & $\ldots$ & $\ldots$ \\
\hline
\end{tabular}




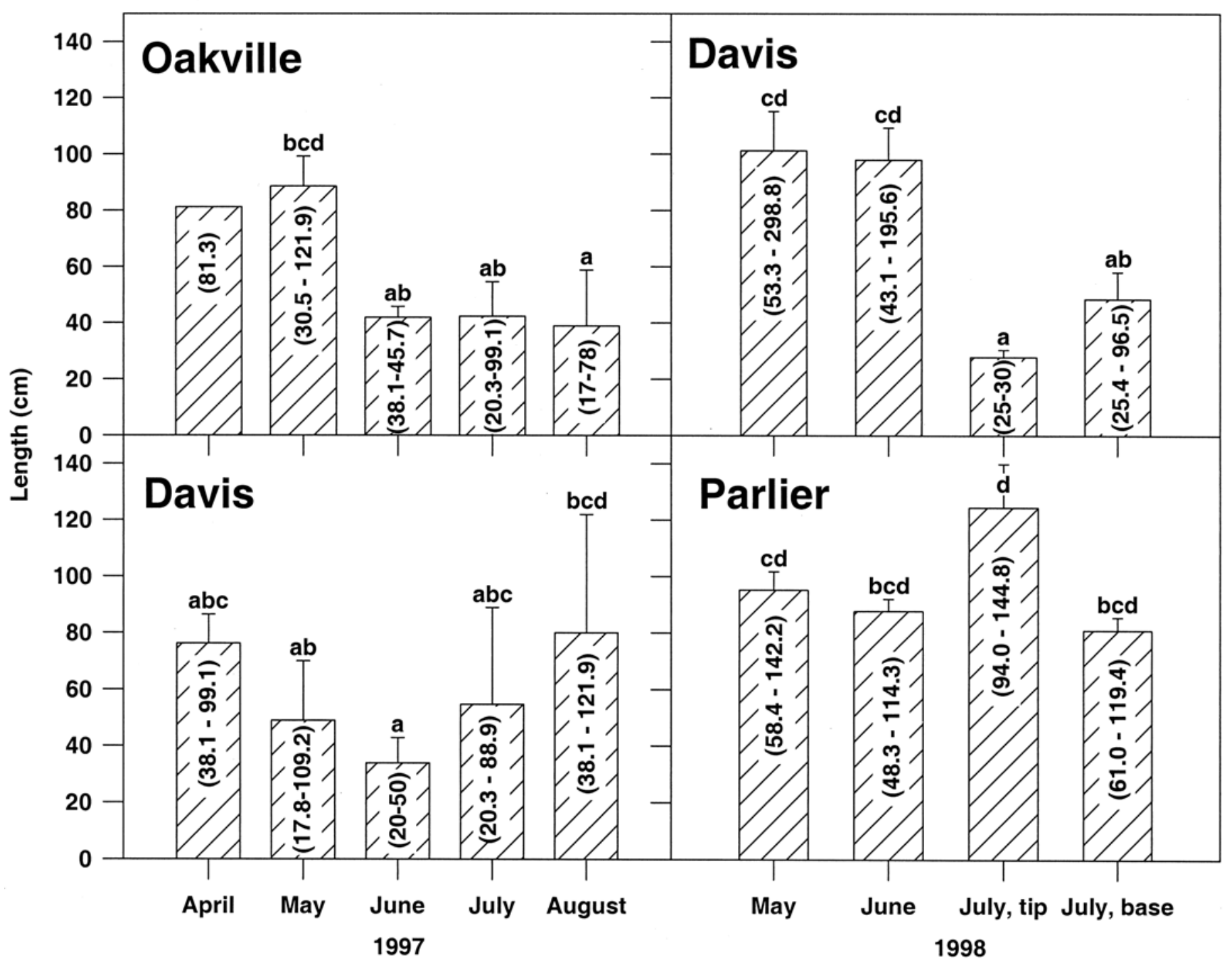

Month of inoculation

Fig. 5. Length of inoculated cane infected with Xylella fastidiosa between the time of inoculation and the following February for 1997 and 1998 inoculations. Average length of infected cane was determined by measuring the distance from the point of inoculation to the farthest known point of infection along the cane for several canes and dividing by the total number of canes. Bars with the same letter are not significantly different $(P<0.05)$ according to Fisher's least significant difference test. Error bars represent standard errors of the mean. Number of canes collected (n): for Oakville and Davis sites in $1997, n=72$ and 49 and for Davis and Parlier site in 1998, $n=106$ and 122. Numbers in parentheses indicate ranges (centimeters).

spatial pattern of PD in California $(14,16)$ are consistent with the hypothesis that summer infections do not establish many chronic infections $(17,19)$. By infecting the basal portions of canes, GWSS could change this situation in California by increasing the percentage of chronic infection from summer inoculations, when the vine-to-vine spread of $X$. fastidiosa should be highest. This could increase the rate of change in PD incidence from its more or less linear annual rate of increase typical for California $(9,16$, 23) to an exponential rate of increase typical of secondary spread that is typically seen where GWSS is present in vineyards (2).

We confirmed that field vines recover from PD. However, further studies need to determine what factors are involved in recovery of grapevines from PD. Our studies indicate that normal winter pruning in vineyards may be a major factor in recovery. Although the most striking differences in recovery were between vines inoculated during April and May versus vines inoculated during June through August, the recovery of vines inoculated in April or May in all locations showed that even some vines that had contiguous infection with $X$. fastidiosa into cordons cleared their infections with $X$. fastidiosa during winter dormancy. Our data are also consistent with other evidence (13) that winter climate limits the geographic distribution of PD in the United States, by the effects of cold temperature on pathogen survival (18).

\section{ACKNOWLEDGMENTS}

This work was supported by the California North Coast Pierce's Disease Task Force, the American Vineyard Foundation, the Viticulture Consortium, and the Andre Tchelistcheff Scholarship fund. This study is part of the Ph.D. dissertation of H. Feil.

\section{LITERATURE CITED}

1. Baker, K. F. 1972. The U. C. system for producing healthy containergrown plants through the use of clean soil, clean stock, and sanitation. Univ. Calif. Ext. Serv. Man. 23.

2. Blua, M. J., Phillips, P. A., and Redak, A. A. 1999. A new sharpshooter threatens both crops and ornamentals. Calif. Agric. 53:22-25.

3. Davis, M. J., Purcell, A. H., and Thompson, S. V. 1978. Pierce's disease 
of grapevines: Isolation of the causal bacterium. Science 199:75-77.

4. Davis, M. J., Raju, B. C., Brlansky, R. H., Lee, R. F., Timmer, I. W., Norris, R. C., and McCoy, R. E. 1983. Periwinkle wilt bacterium: Axenic culture, pathogenicity, and relationships to other gram-negative, xyleminhabiting bacteria. Phytopathology 73:1510-1515.

5. Feil, H. 2001. Effects of temperature on the epidemiology of Pierce's disease. Ph.D. diss. University of California, Berkeley.

6. Feil, H., and Purcell, A. H. 2001. Temperature-dependent growth and survival of Xylella fastidiosa in vitro and in potted grapevines. Plant Dis. 85:1230-1234.

7. Goheen, A. C., and Hopkins, D. L. 1988. Pierce's disease. Pages 44-45 in: Compendium of Grape Diseases. R. C. Pearson and A. C. Goheen, eds. The American Phytopathological Society, St. Paul, MN.

8. Goodwin, P., and Purcell, A. H. 1992. Pierce's disease. Pages 76-84 in: Grape Pest Management, 2nd ed. R. C. Pearson and A. C. Goheen, eds. Division of Agriculture and Natural Resources, University of California, Oakland.

9. Hewitt, W. B., Frazier, N. W., and Freitag, J. H. 1949. Pierce's disease investigations. Hilgardia 19:207-264.

10. Hill, B. L., and Purcell, A. H. 1995. Multiplication and movement of Xylella fastidiosa within grape and four other plants. Phytopathology 85:1368-1372.

11. Hill, B. L., and Purcell, A. H. 1995. Acquisition and retention of Xylella fastidiosa by an efficient vector, Graphocephala atropunctata. Phytopathology 85:209-212.

12. Hill, B. L., and Purcell, A. H. 1997. Populations of Xylella fastidiosa in plants required for transmission by an efficient vector. Phytopathology 87:1197-1201.

13. Hopkins, D. L. 1976. Pierce's disease of grapevines. Am. Wine Soc.
8:26-27

14. Hopkins, D. L., and Adlerz, W. C. 1988. Natural hosts of Xylella fastidiosa in Florida. Plant Dis. 72:429-431.

15. Little, T. M., and Hills, F. J. 1978. Agriculture Experimentation: Design and Analysis. John Wiley \& Sons, New York.

16. Purcell, A. H. 1974. Spatial patterns of Pierce's disease in the Napa Valley. Am. J. Enol. Vitic. 25:162-167.

17. Purcell, A. H. 1975. Role of the blue-green sharpshooter, Hordnia circellata, in the epidemiology of Pierce's disease of grapevines. Environ. Entomol. 4:745-752.

18. Purcell, A. H. 1980. Environmental therapy for Pierce's disease of grapevines. Plant Dis. 64:388-390.

19. Purcell, A. H. 1981. Vector preference and inoculation efficiency as components of varietal resistance to Pierce's disease in European grapes. Phytopathology 71:429-435.

20. Purcell, A. H. 1989. Homopteran transmission of xylem-inhabiting bacteria. Adv. Dis. Vector Res. 6:243-266.

21. Purcell, A. H., and Saunders, S. R. 1999. Glassy-winged sharpshooters expected to increase plant disease. Calif. Agric. 53:26-27.

22. Smart, C. D., Hendson, M., Guilhabert, M. R., Saunders, S. R., Friebertshauser, G., Purcell, A. H., and Kirkpatrick, B. C. 1998. Seasonal detection of Xylella fastidiosa in grapevines with culture, ELISA and PCR. (Abstr.) Phytopathology 88(suppl.):S83.

23. Van der Plank, R. E. 1963. Plant Diseases: Epidemics and Control. Academic Press, New York.

24. Wells, J. M., Raju, B. C., Hung, H. Y., Weisberg, W. G., Mandelco-Paul, L., and Brenner, D. J. 1987. Xylella fastidiosa gen. nov., sp. nov.: Gramnegative, xylem-limited, fastidious plant bacteria related to Xanthomonas spp. Int. J. Syst. Bacteriol. 37:136-143. 